\title{
Роль иракской нефти в стратегии США
}

\author{
Я. Дажанаби, Е.А. Козуб \\ Национальный исследовательский Нижегородский государственный университет \\ им. Н.И. Лобачевского, \\ Россия, 603005, Нижний Новгород, улица Ульянова, 2 \\ E-mail:yacoobsabih@gmail.com, katya-kozub@yandex.ru
}

\begin{abstract}
Аннотация. В статье рассматривается роль нефтяного фактора в присутствии сил Соединённых Штатов Америки в Ираке в исторической ретроперспективе. Авторы анализируют геостратегические, экономические и политические интересы США в регионе Персидского залива, в частности, в Ираке. Делается вывод, что оккупация Ирака силами Соединённых Штатов была направлена не на борьбу с терроризмом, а прежде всего преследовала цель получить контроль над разработкой богатых энергоресурсов Ирака, что также дало возможность установить цены на нефть. Кроме того, в интересах американского правительства было не допустить доминирование других международных акторов в данном регионе и избежать конкуренции в борьбе за энергоресурсы.
\end{abstract}

Ключевые слова: Ирак, США, Ближний Восток, оккупация, нефть, терроризм, реализация, стратегия.

Для цитирования: Дажанаби Я., Козуб Е.А. 2020. Роль иракской нефти в стратегии США. Via in tempore. История. Политология, 47 (4): 904-911. DOI: 10.18413/2687-0967-2020-47-4-904-911.

\section{The role of Iraqi oil in US strategy}

\author{
Ya. Janabi, Ekaterina A. Kozub \\ National Research Nizhny Novgorod State University named after N.I. Lobachevsky, \\ 2 Ulyanova St., 603005, Nizhny Novgorod, Russia \\ E-mail:yacoobsabih@gmail.com, katya-kozub@yandex.ru
}

\begin{abstract}
The article is devoted to the study of the role of the oil factor in the presence of the United States forces in Iraq in historical retrospect. The authors analyze the geostrategic, economic and political interests of the United States in the Persian Gulf region, in particular, in Iraq and the events related to the competitive struggle of international actors for the opportunity to dominate in this region. The conclusion drawn in this article is that the occupation of Iraq by the United States forces was not aimed at fighting terrorism, but primarily aimed at gaining control over the development of Iraq's rich energy resources, which also makes it possible to set oil prices, besides, it was in the interests of the American government to prevent the dominance of other international actors in the region. The political actions of American officials in Iraq helped to revive the American economy: increased trade in weapons and the flow of oil in the Persian Gulf and Iraq to the United States. Iraq has become another political victim in the competition of the world's hegemons.
\end{abstract}

Keywords: Iraq, the USA, Middle East, occupation, oil, terrorism, implementation, strategy.

For citation: Janabi Ya., Kozub E.A. 2020. The role of Iraqi oil in US strategy. Via in tempore. History and political science, 47 (4): 904-911 (in Russian). DOI: 10.18413/2687-0967-2020-47-4-904-911. 
Актуальность темы влияния энергетического фактора на политические действия какого-либо государства с каждым годом повышается. В настоящее время нефть является одним из самых востребованных видов энергоресурсов, торговлю которым можно назвать важнейшим элементом современных мирохозяйственных связей. Она играет ключевую роль в управлении жизненно важными секторами, такими как экономический, сервисный и сектор коммерческой деятельности. Одной из целей американского правительства является установление контроля над мировыми источниками нефти. Как известно, эта колониальная империя, а также её трансконтинентальные компании и их владельцы на протяжении истории уже не раз не колеблясь уничтожали целые страны в поисках нефти. Монополистические нефтяные компании в США были и являются собственностью частного капитала. Международный нефтяной картель в своем составе собрал союз частного капитала и капитала монопольного государства в ряде крупных империалистических стран. Согласно исследованиям, 70\% запасов нефти находятся в ближневосточном регионе, именно по этой причине присутствие в данном регионе входит в стратегические интересы США. С 1925 года (в этом году были обнаружены запасы нефти в Ираке) Ирак стал ощущать на себе влияние колониальной империалистической оккупации, которая продолжается до сих пор [Егорин, 2016]. Проблема исследования заключается в том, что правительство Соединённых Штатов Америки на протяжении долгого периода времени оккупировало иракские территории, чтобы достичь своих долгосрочных целей и стать доминирующей силой на территории этого государства.

Объектом данного исследования являются энергоносители, находящиеся на территории Ирака, а предметом - факторы присутствия сил Соединённых Штатов Америки в Ираке. Методологические основы исследования заключаются в использовании системного подхода при написании работы. В качестве основных исследовательских методов были использованы следующие: исторический метод - для раскрытия ретроспективы и развития отношений и взаимодействия между США и Ираком в ближайшие несколько десятилетий; сравнительный метод - для сопоставления характера и масштабов деятельности США в ближневосточном регионе, в частности в Ираке на различных этапах; индуктивный метод - для проведения анализа от частного к общему - от влияния действий США на Ирак к влиянию действий США на ситуацию в мире в целом.

В исследовании был использован ресурсно-акторный подход, в рамках которого была проанализирована ресурсная база и деятельность США, а также негосударственных акторов, принимающих непосредственное участие в реализации внешнеполитического курса страны, их действий в рамках достижения поставленных целей на территории Ирака. Кроме того, применялся контент-анализ выступлений, внешнеполитических документов для определения вектора политики США, а также проблемно-хронологический и идеографический методы, методы анализа, индукции, дедукции, аналогии и обобщения.

Государства Аравийского полуострова, а также государства Персидского залива являются крупнейшим энергетическим резервом во всем мире. Поскольку Ирак - государство, связывающее Европу и регион Индийского океана, стратегической целью империалистов, начиная с прошлого века, было расширение контроля над этой страной. Между Великобританией, Германией, США, Турцией, а также рядом европейских стран была жесткая конкуренция за возможность присутствовать в Ираке и контролировать источники иракской нефти.

Ирак занимает второе место по мировым запасам нефти после Саудовской Аравии, однако реальные запасы в Ираке намного выше. Кроме того, существует возможность открытия новых нефтяных источников при низких затратах на добычу. По этой причине контроль над Ираком означает контроль примерно над четвертью мировых запасов нефти. Также географическое местоположение Ирака позволяет ему контролировать две третьих мировых запасов нефти, которые сосредоточены в Персидском заливе, что, в свою очередь, делает эту страну ещё более важной для США, учитывая геостратегические интересы этой страны. Главная цель Америки в регионе - контролировать экономику Ирака, чтобы получить возможность управления ценами на нефть, в то же время для США важно 
не допустить присутствие европейских стран, таких как Германия и Франция, а также некоторых других стран в Ирак [Сушенцов, 2010]. Говоря о целях США, стоит упомянуть возможность контролировать цены, особенно после финансовой катастрофы, которая потрясла как американскую, так и мировую экономику. Понеся огромные потери, США, с целью избежать повтора этого сценария, перешли на политику слабого доллара. Многие считают, что слабый доллар воплощает конец господства над миром, но на самом деле это не так. Слабость доллара - не что иное, как новая политика, которой управляют Соединенные Штаты, и она душит всех. Политика слабого доллара - это многоцелевая политика, которая отвечает всем интересам США, а не только экономическим. Благодаря этой политике глобальная финансовая система окажется под американским контролем точно так же, как и иракская нефть. Американский контроль над нефтью в Ираке предоставит возможность контролировать цены на нефть в мире и тем самым приведет к серьёзным последствиям, уменьшив до самого низкого уровня цены на нефть Персидского залива. Поскольку нефть Персидского залива важна для её экономики, в конечном итоге это может отразиться на экономическом уровне в этих странах и привести к ослаблению государств Персидского залива и арабских стран в целом, что и является одной из основных геостратегических целей США в регионе [Al-shamhi, 2018].

Важность этого исследования заключается в определении роли иракской нефти в американской стратегии и выявлении причин, по которым энергоресурсы стали одним из основных факторов оккупации Ирака, что в результате привело к смене иракского режима, разрушению инфраструктуры и более того, оказало влияние на весь ближневосточный регион.

Контроль над Ираком, находящимся на перекрестке Востока и Запада, а также соединяющим три континента - Азию, Африку и Европу, -даёт возможность Соединенным Штатам Америки контролировать как государства Персидского залива, так и остальную часть Ближнего Востока. В исследовании высказывается предположение о том, что нефть не является единственным фактором, побудившим США оккупировать Багдад и свергнуть режим Саддама Хусейна. Вероятно, есть и другие не менее значимые причины, такие как защита безопасности Израиля и его союзников в регионе, то есть некоторых арабских стран Персидского залива, или возможность контролировать и сдерживать Иран, а также ограничить его ядерную программу. В то же время можно предположить, что все эти причины взаимосвязаны, и, таким образом, нефть не является основным фактором присутствия США в Ираке.

Ирак имеет особое значение для американцев не только по причине залежей там богатых энергетических ресурсов, но и благодаря таким факторам, как уникальные географическое и геополитическое расположение, а также богатая история. Он является одной из крупнейших стран в регионе Ближнего Востока и Северной Африки. В регионе Ирак конкурирует с ведущими региональными экспортерами энергоресурсов, а также с другими крупными экономиками региона - Турцией и Египтом [Багдасаров, 2016]. Ирак является стратегически значимым государством, так как сухопутные и воздушные пути из Европы в страны Ближнего Востока и Южной Азии проходят через его территории. Кроме того, он является мостом, связывающим Персидский залив и Средиземное море через сирийскую территорию и Красное море, через иорданскую территорию с Персидским заливом, через порт Умм-Каср. Тот, кто имеет контроль над Ираком, может контролировать с иракской территории соседние страны - Иран, Сирию, иракский и турецкий Курдистан, а также всю зону Персидского залива [Aboud, 2014].

Нефть в Ираке была обнаружена в 1925 году на месторождении Киркук, а затем были обнаружены другие нефтяные месторождения в центральном и южном Ираке, в частности в городе Басра [Mejcher, 1980]. Отрасль развивалась достаточно слабо. В 1932 году Ирак получил независимость от Великобритании, что, в свою очередь, ослабило её контроль за нефтяным производством в стране, однако компания «Ирак Петролеум», доминировавшая в нефтяной отрасли государства до 1958 года, контролировалась иностранными капиталами, что помогло укрепиться британским, французским и амери- 
канским военно-стратегическим позициям на Ближнем Востоке в рамках строительства нефтепровода к Средиземному морю и финансового участия в сооружении объектов транспортной инфраструктуры региона [Chatelus, 1993]. Чтобы ослабить свою зависимость от иностранного нефтяного капитала, правительства Ирака, Египта и Турции строили национальные нефтеперерабатывающие заводы, однако американские и другие иностранные компании продолжали контролировать иракскую нефть. С момента национализации нефтяной промышленности в Ираке, произошедшей в 1972 году, согласно статистике, иракские запасы нефти превышали 112 миллиардов баррелей, в то время как доля недоказанных запасов превышала 362 миллиарда баррелей [Абиди, 2007]. Наиболее важной характеристикой иракской нефти являлась недорогая стоимость добычи, не превышающая 2 доллара за баррель, в то же время стоимость добычи американской нефти была 14 долларов за баррель [a country that is rich..., 2019]. К настоящему времени Ирак стал четвертой страной в мире по экспорту нефти и вторым крупнейшим производителем среди стран ОРЕС. Он располагает более чем 147 миллиардами баррелей доказанных запасов нефти около 9 \% мировых поставок - и очень высоким соотношением запасов к фактической добыче (4,6 млн баррелей в сутки в 2018 году). Также в этой стране находятся 125,6 трлн кубометров запасов газа [Salema, 2010]. Учитывая тот факт, что Ирак считается одной из крупнейших нефтяных держав, которые оказывают значительное влияние на мировые поставки энергоресурсов, становится понятен интерес США к этому государству.

Железнодорожные и продовольственные компании, а также банки и автомобильная промышленность занимали ведущее место среди американских компаний начиная с 1929 года, но с 1979 года ведущая роль перешла нефтяной промышленности, доминирующее место по получению прибыли в которой занимали и продолжают занимать такие нефтяные компании, как Exxon, Mobil, Texas и др. [Ван-Вактор, 2014].

После нефтяного и энергетического кризисов 1970-х годов госсекретарь США Генри Киссинджер пригрозил применить военную силу против арабских стран, поднявших цены на нефть. Однако ситуация изменилась на рубеже 1979-1980 гг., когда советские войска пришли в Афганистан. Президентом США Джимми Картером была провозглашена Доктрина Картера, согласно которой Персидский залив считался районом, имеющим жизненно важное значение для Соединенных Штатов и всего западного мира, в связи с этим было принято решение направить военно-морские силы к их берегам, чтобы обеспечить продолжение поставок нефти оттуда.

Во время кризиса в Персидском заливе 1990 года газета American Herald Tribune написала 27 августа 1990 года: «Любой американец, знающий политику США, прекрасно понимает, что Соединенные Штаты не борются за демократию против Ирака, потому что в арабском мире нет демократии, и не борются за Кувейт. Соединенные Штаты перебрались в Ирак, чтобы контролировать богатства - топливную промышленность» [al-Ardawi, 2019].

После терактов 11 сентября 2001 года произошли изменения в стратегическом планировании Америки. Терроризм стал одной из основных форм вооруженного конфликта на международной арене. В связи с этим, согласно новой стратегии США, борьба с терроризмом стала одной из основных целей этого государства. Период, последовавший за событиями 11 сентября 2001 года, стал свидетельством серьезных изменений в стратегии Соединенных Штатов, которая вышла на новый этап. Соединенные Штаты Америки возглавили войну с терроризмом и включили некоторые страны мира, в основном страны ближневосточного региона, в список государств-спонсоров террористов. В целях ликвидации терроризма (в частности в Ираке), в США была создана новая стратегия, которая также была настроена на то, чтобы перестроить карту мира в соответствии с американскими интересами. С того момента, как президент США Джордж Буш ввел термин «ось зла», определив Ирак как одну из трех сторон, наряду с Ираном и Северной Кореей, Соединенные Штаты начали в ходе войны в 2003 году работать над достижением ряда целей: политических, геостратегических и экономических. В данном исследовании уделяется 
внимание именно роли экономического фактора, который, как предполагается, является причиной войны в Ираке больше, чем просто захват нефти для внутреннего потребления США. Интересен тот факт, что в период американской оккупации Ирака в 2003 году, основными целями которой были заявлены борьба с терроризмом, а также уничтожение оружия массового поражения, американские силы охраняли от разрушений объекты нефтяной промышленности неподалёку от месторождений нефти, бомбардировки проводились с особой осторожностью, кроме того, были приняты все возможные меры для тушения подожженных нефтяных колодцев [Barnet, 2016].

Такие детали подтверждают истинную причину американской оккупации Ирака. Стоит упомянуть тот факт, что в 2003 году Соединённые Штаты вывели свои войска с баз, расположенных в Саудовской Аравии, в ожидании, что Ирак станет лучшей заменой, а оккупированные месторождения энергоресурсов позволят Вашингтону быть уверенными в стабильном положении энергетического сектора Штатов. Соединенные Штаты навязали Ираку экономическую стратегию, которая предусматривает следующее: полная открытость иракских институтов миру, принятие сильных и привлекательных стимулов для развития частного сектора, достижение конвергенции и экономической интеграции [Ashford, 2018]. В дополнение к американским усилиям по восстановлению Ирака с целью оживления американской экономики и решения такой проблемы, как войны, программа реконструкции Ирака была описана как крупнейший в мире проект реконструкции после проекта Маршалла, который государства предприняли для восстановления Европы после Второй мировой войны [al-Azzawi, 2014].

События 11 сентября 2001 года представляют собой исторический промежуток между двумя фазами и качественным изменением в общем поведении Соединенных Штатов. Поскольку период после 2001 года совпал с нахождением у власти администрации Буша, это оказало значительное влияние на фундаментальные сдвиги в общих тенденциях внешней политики государства. Администрация США привела большое количество ложных аргументов, ставших причиной начала войны с Ираком, включая обвинение данного государства в террористических связях, а также в причастности к событиям 11 сентября 2001 года и в обладании оружием массового уничтожения. Но на самом деле война против Ирака, по сути, была «нефтяной». Ирак является для Соединенных Штатов ключом ко вторым по объему запасам нефти после месторождений Саудовской Аравии. Все страны региона Персидского залива владеют в общей сложности двумя третями мировых запасов нефти [Айдрс, Меланьина, 2016]. Практически каждый крупный торговый партнер США в Азии зависит от стабильного потока нефти из Персидского залива - и Европа также является ключевым импортером. Развивающиеся государства во всем мире зависят от нефтяных портов Персидского залива и в частности Ирака, поэтому Соединенным Штатам необходимо присутствовать в Ираке и продолжать контролировать ситуацию в регионе [Шумилин, 2007].

Кроме того, важно не допустить присутствие в Ираке других международных акторов, в частности России и Китая. Так, политическими официальными лицами США было сделано заключение о том, что вторжение в Ирак является решением, которое предоставляет возможность доминировать в добыче нефтяных богатств страны, а также контролировать регион [Okabi, 2015].

Таким образом, нефть, являющаяся одним из главных инструментов мирового контроля, является важным фактором, послужившим вторжению американских сил в Ирак. Победа в Ираке позволила администрации США добиться глобальных завоеваний, а также прямого господства в этом государстве [Al-Falah, 2019]. Нефть является самой важной политической целью американской внешней политики, в связи с этим есть риск возникновения еще одной иракской войны [lname, 2014]. Трудно не согласиться с замечанием британского журналиста Роберта Фиска: «Соединенным Штатам необходимо будет контролировать глобальные источники нефти..., Соединенные Штаты не вторглись бы в Ирак, если бы Ирак экспортировал свеклу, а не контролировал 25 \% мировых запасов нефти» [Makarim, 2010]. 
Опираясь на все приведённые факты, в результате исследования были сделаны следующие выводы: кроме осуществления геостратегических, экономических и политических интересов, основной целью Соединённых Штатов Америки в Ираке является нефть. Именно данный факт привел к разработке новой стратегии в США и прояснил важность Ирака для обслуживания американских интересов с точки зрения реализации ближневосточного проекта. Однако не стоит забывать, что доминирование в Ираке даёт возможность американскому правительству контролировать Иран и быть готовыми ответить на любые вызовы, которые могут быть предприняты этим государством. Также был сделан вывод, что в случае если США почувствует, что какой-либо международный актор заинтересовался энергоресурсами Ирака, то Вашингтон будет готов использовать вооруженные силы. То есть нефть можно назвать одной из основных причин дестабилизации безопасности в регионе. Кроме того, оккупация Ирака позволила США оказаться в сердце Ближнего Востока и оттуда навязывать свою гегемонию государствам Персидского залива, а также обеспечить присутствие американских военных баз в регионе, которые в случае любых чрезвычайных ситуаций, затрагивающих безопасность Соединенных Штатов или безопасность региона, позволят быть близко к этим местам и быстро отреагировать на такую ситуацию.

Таким образом, Соединенным Штатам Америки была нужна иракская война не для того, чтобы избавить иракский народ от прежнего режима или установить равновесие между арабским миром и Израилем. Руководство США получило контроль над иракской нефтью, что дало возможность вывести Соединенные Штаты на вершину международной системы и поддержать идею однополярной системы международных отношений после появления стратегии президента Джорджа Буша-младшего. Появление новой стратегии дало положительные результаты для Соединенных Штатов, среди них навязывание их гегемонии в регионе Персидского залива. Война, в свою очередь, способствовала оживлению американской экономики: увеличение товарооборота по торговле оружием и потока нефти в Персидском заливе и Ираке в Соединенные Штаты.

Соединённым Штатам Америки удалось достичь своих целей за счёт оккупации Ирака, которая, согласно их заявлениям, была необходимым шагом в борьбе с терроризмом, однако на основании приведённых раннее фактов можно сделать вывод, что заявленные американским правительством цели были предлогом для проникновения на территорию Ирака и установления доминирования на территории этого государства. Следовательно, Ирак стал очередной политической жертвой в конкуренции мировых гегемонов.

\section{Список литературы}

1. Абиди Х.Л. Иракская нефть и нефтяная политика в Ираке и в регионе в свете американской оккупации: в 3 т. / Х.Л. аз-Забиди. - Багдад: Иракский центр исследований, 2007. - Т. 1. - 366 с.

2. Айдрус И.А.З., Меланьина М.В. Экономические санкции в условиях глобализации: проблемы теории и современная практика Ирака // Азия: вектор развития внешнеэкономического сотрудничества с Россией в условиях санкций. Ежегодник - 2016. Под редакцией Л.В. Шкваря. Москва, 2016. С. 48-76.

3. Багдасаров С.А. Ближний Восток. Вечный конфликт. М.: Эксмо, 2016. 288 с.

4. Ван-Вактор С.А. Нефть благословенная и проклинаемая. Международный нефтегазовый бизнес от скважины до бензоколонки / С.А. Ван-Вактор. - М.: Альпина Паблишер, 2014. - 240 с.

5. Ергин Д. Добыча. Всемирная история борьбы за нефть, деньги и власть. - М.: Альпина Паблишер, 2016. С. 154.

6. Сушенцов А.А. Эволюция политических приоритетов США в Ираке / А.А. Сушенцов // США - Канада. Экономика, политика, культура. - 2010. - № 7. - С. 53-66.

7. Шумилин, А. И. Проблема нефти и перспектива вывода американских войск изИрака/ А. И. Шумилин// США- Канада. Экономика, политика, культура. - С. 37-54.

8. Aboud Ali, 2014. American strategy for the Iraqi development. - Available at: http://www.ahewar.org/debat/show.art.asp?aid=420136\&r (accessed 28 February 2020) (in Arab.). 
9. A country that is rich and a people that can't find food. What do you know about Iraqi oil. 2019. Available at: http://khaleej.online/Gbz4Mn (accessed 2 March 2020) (in Arab.).

10. Al-shamhi Rahman, 2018. American ambitions for the Iraqi and Syrian oil threaten the organization of OPEC. Available at: http://tishreen.news.sy/?p=21359 (accessed 28 February 2020) (in Arab.).

11. Al-Falah Abdul-Khaliq. 2019. «Iraq to where ... civilised dialogue has moved». Available at: http://www.ahewar.org/debat/show.art.asp?aid=657203 (accessed 4 March 2020) (in Arab.).

12. Chatelus M. Iraq and Its Oil: Sixty-five Years of Ambitions and Frustration // Iraq: Power and Society / ed. by D. Hopwood. - Oxford: St. Antony's College, 1993. - P. 141-161.

13. Haled al-Ardawi, 2019. Iraq and the United States of America, study the future foreign policy of Iraq. Available at: https://abu.edu.iq/sites/default/files/jurnals/abu/3/3-13.pdf (accessed 3 March 2020) (in Arab.).

14. Heba Burhan al-Azzawi. 2014. The events of September 11, 2001 and its impact on international politics. Available at: http://www.ahewar.org/debat/show.art.asp?aid=408271 (accessed 5 March 2020) (in Arab.).

15. Hamisa Okabi. 2015. Oil research in the US-Arab relations on the example of Algeria (1990-2014). Available at: http://www.ahewar.org/debat/show.art.asp?aid=657203 (accessed 5 March 2020) (in Arab.).

16. Mejcher H. Die Politic und das Ol im Nahen Osten. Bd. I. Der Kampf der Machte und Konzerne vor dem Zweiten Weltkrieg. - Stuttgart: Klett-Cotta, 1980.

17. Salema Ahmed. 2010. America has succeeded in achieving its goals of occupying Iraq. Available at: http://khaleej.online/Gbz4Mn (accessed 6 March 2020) (in Arab.).

18. Saleh lname. 2014. American policy in Iraq: divide and conquer. Available at: http://www.alriyadh.com/19560 (accessed 3 March 2020) (in Arab.).

19. Makarim Ibrahim. 2010. Is oil the cause of America's war with Iraq? Available at: http://www.ahewar.org/debat/show.art.asp?aid=224067 (accessed 4 March 2020) (in Arab.).

20. Thomas P.M. Barnet. America's Post-Oil Grand Strategy, 18 February 2016. - Available at: http:// thomaspmbarnett. squarespace.com/globlo gization/2016/2/18/americas-post-oil-grand-strategy.html (accessed 7 March 2020).

\section{References}

1. Abidi Kh.L. Irakskaya neft' i neftyanaya politika $v$ Irake $\mathrm{i} v$ regione $\mathrm{v}$ svete amerikanskoy okkupatsii: $\mathrm{v} 3 \mathrm{t}$. [Iraqi oil and oil policy in Iraq and the region in the light of the American occupation: in 3 vols.] / Kh.L. az-Zabidi. - Bagdad: Irakskiy tsentr issledovaniy, 2007. - T. 1. - 366 s. (in Russian)

2. Aydrus I.A.Z., Melan'ina M.V. Ekonomicheskie sanktsii v usloviyakh globalizatsii: problemy teorii i sovremennaya praktika Iraka // Aziya: vektor razvitiya vneshneekonomicheskogo sotrudnichestva s Rossiey v usloviyakh sanktsiy Ezhegodnik - 2016. Pod redaktsiey L.V. Shkvarya [Economic sanctions in the context of globalization: problems of theory and modern practice of Iraq // Asia: the vector of development of foreign economic cooperation with Russia in the context of sanctions. Edited by L.V. Shkvar]. Moskva, 2016. S. 48-76 (in Russian).

3. Bagdasarov S.A. Blizhnij Vostok. Vechnyj konflikt [The Middle East. Eternal conflict]. Moscow: Eksmo, 2016. 288 p. (in Russian).

4. Van-Vaktor S.A. Neft' blagoslovennaya i proklinaemaya. Mezhdunarodnyy neftegazovyy biznes ot skvazhiny do benzokolonki [Oil blessed and cursed. International oil and gas business from a well to a gas station]. / S.A. Van-Vaktor. - M.: Al'pina Pablisher, 2014. - 240 s. (in Russian).

5. Ergin D. Dobycha. Vsemirnaya istoriya bor'by za neft', den'gi i vlast' [The world history of the struggle for oil, money and power]. - M.: Al'pina Pablisher, 2016. S. 154 (in Russian).

6. Sushentsov A.A. Evolyutsiya politicheskikh prioritetov SShA v Irake [The Problem of oil and the prospect of withdrawal of American troops from Iraq]. / A.A. Sushentsov // SShA - Kanada. Ekonomika, politika, kul'tura. - 2010. - № 7. - S. 53-66 (in Russian).

7. Shumilin A.I. Problema nefti i perspektiva vyvoda amerikanskikh voysk iz Iraka [The Problem of oil and the prospect of withdrawal of American troops from Iraq]. / A.I. Shumilin // SShA - Kanada. Ekonomika, politika, kul'tura. - S. 37-54. Ashford E. Unbalanced: Rethinking America's Commitment to the Middle East // Strategic Studies Quarterly, Spring 2018, pp. 127-148 (in Russian).

8. Aboud Ali, 2014. American strategy for the Iraqi development. - Available at: http://www.ahewar.org/debat/show.art.asp?aid=420136\&r (accessed 28 February 2020) (in Arab.). 
9. A country that is rich and a people that can't find food. What do you know about Iraqi oil. 2019. Available at: http://khaleej.online/Gbz4Mn (accessed 2 March 2020) (in Arab.).

10. Al-shamhi Rahman, 2018. American ambitions for the Iraqi and Syrian oil threaten the organization of OPEC. Available at: http://tishreen.news.sy/?p=21359 (accessed 28 February 2020) (in Arab.).

11. Al-Falah Abdul-Khaliq. 2019. «Iraq to where ... civilised dialogue has moved». Available at: http://www.ahewar.org/debat/show.art.asp?aid=657203 (accessed 4 March 2020) (in Arab.).

12. Chatelus M. Iraq and Its Oil: Sixty-five Years of Ambitions and Frustration // Iraq: Power and Society / ed. by D. Hopwood. - Oxford: St. Antony's College, 1993. - P. 141-161.

13. Haled al-Ardawi, 2019. Iraq and the United States of America, study the future foreign policy of Iraq. Available at: https://abu.edu.iq/sites/default/files/jurnals/abu/3/3-13.pdf (accessed 3 March 2020) (in Arab.).

14. Heba Burhan al-Azzawi. 2014. The events of September 11, 2001 and its impact on international politics. Available at: http://www.ahewar.org/debat/show.art.asp?aid=408271 (accessed 5 March 2020) (in Arab.).

15. Hamisa Okabi. 2015. Oil research in the US-Arab relations on the example of Algeria (1990-2014). Available at: http://www.ahewar.org/debat/show.art.asp?aid=657203 (accessed 5 March 2020) (in Arab.).

16. Mejcher H. Die Politic und das Ol im Nahen Osten. Bd. I. Der Kampf der Machte und Konzerne vor dem Zweiten Weltkrieg. - Stuttgart: Klett-Cotta, 1980.

17. Salema Ahmed. 2010. America has succeeded in achieving its goals of occupying Iraq. Available at: http://khaleej.online/Gbz4Mn (accessed 6 March 2020) (in Arab.).

18. Saleh lname. 2014. American policy in Iraq: divide and conquer. Available at: http://www.alriyadh.com/19560 (accessed 3 March 2020) (in Arab.).

19. Makarim Ibrahim. 2010. Is oil the cause of America's war with Iraq? Available at: http://www.ahewar.org/debat/show.art.asp?aid=224067 (accessed 4 March 2020) (in Arab.).

20. Thomas P.M. Barnet. America's Post-Oil Grand Strategy, 18 February 2016. - Available at: http:// thomaspmbarnett. squarespace.com/globlo gization/2016/2/18/americas-post-oil-grand-strategy.html (accessed 7 March 2020).

\section{ИНФОРМАЦИЯ ОБ АВТОРАХ}

Дажанаби Якуб Сабих Хасан, аспирант Института международных отношений и мировой истории (направление: 41.06.01 Политические науки и регионоведение) ФГАОУ ВО «Национальный исследовательский Нижегородский государственный университет им. Н.И. Лобачевского», г. Нижний Новгород, Россия

Козуб Екатерина Алексеевна, магистрант Института международных отношений и мировой истории (направление: 41.04.01 Зарубежное регионоведение) ФГАОУ ВО «Национальный исследовательский Нижегородский государственный университет им. Н.И. Лобачевского», г. Нижний Новгород, Россия

\section{INFORMATION ABOUT THE AUTHORS}

Yaqoob Sabeeh Hasan Janabi, post-graduate student of the Institute of International Relations and World History (direction: 41.06.01 Political Sciences and Regional Studies), National Research Lobachevsky State University of Nizhni Novgorod, Nizhny Novgorod, Russia

Ekaterina A. Kozub, Master student at the Institute of International Relations and World History (direction: 41.04.01 Foreign Regional Studies), National Research Lobachevsky State University of Nizhni Novgorod, Nizhny Novgorod, Russia 